\title{
Sources other than unused sawdust can introduce Klebsiella pneumoniae into dairy herds
}

\author{
B. Verbist, ${ }^{\star 1}$ V. Piessens, $†$ A. Van Nuffel, ${ }^{*}$ L. De Vuyst, $\ddagger$ M. Heyndrickx, $†$ L. Herman, ${ }^{\star} \dagger$ E. Van Coillie, $\dagger$ \\ and S. De Vliegher§ \\ *Institute for Agricultural and Fisheries Research, Technology and Food Science Unit, Agricultural Engineering, Merelbeke, Belgium 9820 \\ †Institute for Agricultural and Fisheries Research, Technology and Food Science Unit, Food Safety, Melle, Belgium 9090 \\ $\ddagger$ Vrije Universiteit Brussel, Research Group of Industrial Microbiology and Food Biotechnology, Brussels, Belgium 1050 \\ $\S$ Ghent University, Faculty of Veterinary Medicine, Department of Reproduction, Obstetrics and Herd Health, Merelbeke, Belgium 9820
}

\begin{abstract}
A longitudinal study was carried out to detect intramammary infections caused by Klebsiella pneumoniae and to identify potential sources of this bacterial species in the environment of the cows. The study was performed in 6 well-managed Belgian dairy herds from May 2008 to May 2009. Monthly $(\mathrm{n}=13)$, unused and used sawdust bedding samples as well as individual quarter milk and feces samples were collected from 10 randomly selected cohort cows in each herd. Cases of clinical mastitis of all lactating cows in the 6 herds were also sampled $(\mathrm{n}=64)$. From the 3,518 collected samples, $153 \mathrm{~K}$. pneumoniae isolates were obtained, of which 2 originated from milk (clinical mastitis cases). In feces $(\mathrm{n}=728)$, used bedding $(\mathrm{n}=73)$, and unused bedding $(\mathrm{n}=73)$, respectively, $125(17.2 \%), 20$ $(27.4 \%)$, and $6(8.2 \%)$ isolates were found. The isolates were fingerprinted by means of pulsed field gel electrophoresis. In total, 109 different pulsotypes were differentiated, indicating a high degree of genetic diversity within the isolates. All isolates from unused bedding belonged to pulsotypes other than those from the other sources, suggesting that sources other than unused sawdust may introduce $K$. pneumoniae into the herd. Only 2 pulsotypes contained isolates originating from different sources. Pulsotype 10 was found in milk and used bedding and pulsotype 21 was found in feces and used bedding. The 2 milk isolates originated from 2 cows in the same herd but they belonged to a different pulsotype. The results indicate that $K$. pneumoniae can be prevalent in the environment without causing significant mastitis problems. Most cows were shedding $K$. pneumoniae in feces, substantiating findings under very different conditions (i.e., American dairy herds). Contamination of used bedding in the cubicles with $K$. pneumoniae from feces was confirmed, whereas unused
\end{abstract}

Received August 9, 2010.

Accepted March 7, 2011.

${ }^{1}$ Corresponding author: Bert.Verbist@ILVO.Vlaanderen.be bedding was not an important source of $K$. pneumoniae for the environment of the cows.

Key words: environment, intramammary infection, Klebsiella pneumoniae, pulsed field gel electrophoresis

\section{INTRODUCTION}

Gram-negative bacteria, Escherichia coli and Klebsiella species in particular, are a common cause of clinical mastitis in dairy cattle (Erskine et al., 1991; Roberson et al., 2004). For many years, Klebsiella has received less attention than E. coli although Klebsiella species have been reported to threaten udder health in dairy herds as well, either by causing individual clinical mastitis cases (Todhunter et al., 1991; Ribeiro et al., 2008) or by causing mastitis outbreaks (Vecht et al., 1987; Sampimon et al., 2006; Munoz et al., 2007). Production losses and mortality due to IMI caused by Klebsiella are higher compared with those caused by E. coli (Erskine et al., 2002a; Gröhn et al., 2004), and current preventive vaccination and antibiotic therapy have only limited effects (Erskine et al., 2002b; Roberson et al., 2004). Because of the poor response to treatment, hygienic measures are the most appropriate control strategy for Klebsiella mastitis (Munoz et al., 2006). Still, more accurate epidemiological knowledge of the behavior of Klebsiella in dairy herds would help to prevent Klebsiella mastitis problems.

For many years, wood-based bedding materials were considered as the most important source of IMI due to Klebsiella (Vecht et al., 1987; National Mastitis Council, 1999; Sampimon et al., 2006). The most logical prevention strategy was therefore to use inorganic bedding materials. However, several investigations have affirmed the presence and growth of Klebsiella in both organic and inorganic bedding materials (Hogan et al., 1989; Zdanowicz et al., 2004). Moreover, Klebsiella species have a ubiquitous character. In dairy farms Klebsiella has frequently been isolated from feed (Zadoks et al., 2011), milking machine equipment (Munoz et al., 2007), milking machine wash water (Silva and Costa, 
2001), drinking water (Nonnecke and Newbould, 1984; Munoz et al., 2007; Zadoks et al., 2011), and cow skin and mucosae (Nonnecke and Newbould, 1984; Zadoks et al., 2008). Feces have been confirmed to be a source of environmental Klebsiella contamination in US herds (Munoz et al., 2006). This has so far not been shown in European herds, which differ considerably from American herds in management, herd size, feeding, bulk milk SCC, and other factors. A recent Swedish study indicated that fecal shedding of K. pneumoniae is rare, suggesting that a clear distinction exists between the American and European situations (Lektonius et al., 2010), although this has to be substantiated. Of all Klebsiella species, Klebsiella pneumoniae is the most frequently isolated species from quarters with IMI (Nomura et al., 1989a; Roberson et al., 2004; Munoz et al., 2007).

Confirmation of a suspected infection source requires the identification of the same strain of a pathogen in the suspected source and in the target tissue. In many Klebsiella studies, this has been done using only bacteriological cultures combined with phenotypic species identification (Vecht et al., 1987). Currently, identification of $K$. pneumoniae can be achieved by using PCR techniques with species-specific primers (Liu et al., 2008). However, because of strain diversity, strain typing is necessary to identify potential $K$. pneumoniae sources and to evaluate the epidemiological behavior of the $K$. pneumoniae strains. High genetic diversity in mainly clinical mastitis associated $K$. pneumoniae strains (Munoz et al., 2007; Paulin-Curlee et al., 2007, 2008) and in environmental $K$. pneumoniae strains (Munoz and Zadoks, 2007) has been shown.

To distinguish different Klebsiella strains within a species, plasmid profiling (Kikuchi et al., 1995) and phenotypic methods such as biochemical testing (Nonnecke and Newbould, 1984) and capsular typing (Nonnecke and Newbould, 1984; Nomura et al., 1989a,b) have been applied. More recently, pulsed field gel electrophoresis (PFGE; Paulin-Curlee et al., 2007), multi-locus sequence typing (MLST; Paulin-Curlee et al., 2007), and PCR-based genotyping methods such as randomly amplified polymorphic DNA PCR (RAPD; Munoz et al., 2007) and repetitive element primed PCR (rep-PCR; Paulin-Curlee et al., 2007, 2008), have been applied.

The aim of the current longitudinal field study was to identify potential $K$. pneumoniae sources in the environment of dairy cows with PFGE typing and to detect IMI caused by K. pneumoniae. We hypothesized that the majority of cows would shed $K$. pneumoniae in feces and that K. pneumoniae from feces and unused bedding would cause IMI and contaminate the cows' environment.

\section{MATERIALS AND METHODS}

\section{Study Design, Herds, and Cows}

A longitudinal study was carried out in 6 well-managed Belgian dairy herds (herds A to F) from May 2008 to May 2009. The herds adopted the National Mastitis Council (NMC) mastitis prevention and control guidelines (National Mastitis Council, 2008). Based on the data from May 2009, the average herd size was 70 Holstein cows (ranging from 49 to 87) with an average production of $9,368 \mathrm{~kg}$ of milk per cow per year (ranging from 7,147 to 11,665$)$. The average monthly bulk milk SCC during the study period was 137,725 cells/ $\mathrm{mL}$ of milk and ranged from 85,615 to 202,154 .

Cows were housed in freestalls with slatted floor alleys and sawdust-bedded cubicles. The alleys were scraped at least twice a day. Used sawdust bedding was removed 2 or 3 times a day and replaced by unused sawdust bedding. Unused bedding was stored indoors in bulk for future use to be placed in the stalls.

At the beginning of the study, a cohort of 10 clinically healthy cows in each herd was randomly selected within parity blocks ( 4 heifers, 3 cows of second parity, and 3 cows of third or higher parity). Before the end of the study, 20 cows out of 60 were culled (ranging from 0 to 5 per herd). The average time in study was $11.2 \mathrm{mo}$. All cohort cows culled before the 12th month of study $(\mathrm{n}=14)$ were replaced by randomly selected herdmates of the same parity.

\section{Sampling Schedule}

Each month $(\mathrm{n}=13)$, quarter milk samples of all cohort cows were collected aseptically according to the standard procedures (National Mastitis Council, 1999) by the first author of this article. They were frozen in a mobile freezer on the farm and transported frozen to the Milk Control Center Flanders (MCC-Vlaanderen, Lier, Belgium) for bacteriological culture. Cases of clinical mastitis of cohort cows in between monthly samplings were sampled by the herd personnel. In addition, samples of clinical mastitis cases of all other lactating cows in the herd, as detected by the farmers, were collected either by the first author or by the herd personnel. The average incidence rate of clinical mastitis (IRCM, all pathogens) was calculated as by Barkema et al. (1998).

Monthly $(\mathrm{n}=13)$, fecal samples were collected from the rectum of each cohort cow using individual palpation sleeves and they were stored in sterile plastic boxes at $4^{\circ} \mathrm{C}$ for transport to the Animal Health Service Flanders (DGZ Vlaanderen, Drongen, Belgium) laboratory.

Monthly $(\mathrm{n}=13)$, used bedding was collected from the back one-third of $10 \%$ of the cubicles. Per herd and 
per sampling, the collected bedding (approximately 10 L) was commingled and a subsample (approximately $300 \mathrm{~mL}$ ) was stored at $4^{\circ} \mathrm{C}$ for transport to the DGZ laboratory.

Unused bedding was collected monthly $(\mathrm{n}=13)$ using a sample bore $(5.6 \mathrm{~cm}$ diameter, $50 \mathrm{~cm}$ long) at 5 different places in the front of the stock. Commingling and further handling of the samples was the same as for used bedding.

\section{Sampling Processing and Bacterial Isolation}

Bacteriological analysis of individual quarter milk samples was performed as described by Piepers et al. (2007). Quarter milk samples $(10 \mu \mathrm{L})$ were plated on MacConkey's agar (Oxoid Ltd., Basingstoke, UK) for growth of gram-negative bacteria. Lactose-fermenting $\left(\mathrm{Lac}^{+}\right)$pink colonies (1 per positive sample) were grown overnight on tryptone soy agar (TSA) plates (Oxoid Ltd.) at $37^{\circ} \mathrm{C}$ and stored in brain heart infusion broth with $15 \%$ (vol/vol) glycerol at $-80^{\circ} \mathrm{C}$ until further processing.

For isolation of Klebsiella species from fecal and bedding samples, the method described by Munoz et al. (2006) was used. Fecal samples were streaked onto MacConkey's agar containing $10 \mathrm{mg} / \mathrm{L}$ of ampicillin to inhibit growth of $E$. coli. Bedding samples (10 g) were first suspended in $90 \mathrm{~mL}$ of saline and then streaked on MacConkey's agar without ampicillin. Agar plates were incubated overnight at $37^{\circ} \mathrm{C}$ followed by visual assessment for the presence of mucoid pink Klebsiellalike colonies. Suspected colonies (1 per plate) were subcultured onto Columbia agar with $5 \%$ (vol/vol) sheep blood (Oxoid Ltd.) and subjected to biochemical analysis for confirmation at the genus level by transferring onto Kligler iron agar (Oxoid Ltd.), urea agar (Oxoid Ltd.), and esculin agar. Phenotypically confirmed Klebsiella colonies were streaked on TSA and stored as described above.

\section{Identification of Klebsiella pneumoniae by PCR}

Bacterial crude cell lysates were prepared by suspension of a few colonies that were freshly grown on TSA, in $100 \mu \mathrm{L}$ of HPLC water, thermal lysis (10 min at $90^{\circ} \mathrm{C}$ ), followed by vortexing for $1 \mathrm{~min}$ and centrifugation $(14,000 \times g ; 1 \mathrm{~min})$. For identification of $K$. pneumoniae, a PCR method based on 16S-23S internal transcribed spacer was performed, using the primers Pf and Pr2 described by Liu et al. (2008). The PCR assay was performed in a final volume of $25 \mu \mathrm{L}$, containing 1 $\mathrm{U}$ of AmpliTaq DNA polymerase (Applied Biosystems, Foster City, CA), $2.5 \mu \mathrm{L}$ of AmpliTaq Buffer $(10 \times)$, $100 \mu M$ of each dNTP, $1.5 \mathrm{mM} \mathrm{MgCl} 2,25$ pmol of each primer, and $1 \mu \mathrm{L}$ of crude cell lysate. The reaction mixture was subjected to 30 cycles of amplification in a thermal cycler (Cetus 9600, Applied Biosystems). The first cycle was preceded by initial denaturation at $95^{\circ} \mathrm{C}$ for $10 \mathrm{~min}$. Each cycle consisted of denaturation at $95^{\circ} \mathrm{C}$ for $30 \mathrm{~s}$, annealing at $57^{\circ} \mathrm{C}$ for $30 \mathrm{~s}$, and extension at $72^{\circ} \mathrm{C}$ for $20 \mathrm{~s}$. The last cycle was followed by a final extension step at $72^{\circ} \mathrm{C}$ for $10 \mathrm{~min}$. The PCR products were resolved on a 2.0\% (wt/vol) Seakem LE agarose gel (FMC Bioproducts, Rockland, ME).

\section{Typing of Klebsiella pneumoniae Isolates by PFGE}

Strain typing was conducted according to the standardized rapid PFGE PulseNet protocol described by Ribot et al. (2006), with some minor modifications. For digestion, $30 \mathrm{U}$ of $\mathrm{Xba \textrm {I }}$ (Roche Diagnostics, Mannheim, Germany) was used instead of 40 to $50 \mathrm{U}$ and samples were incubated overnight $(16 \mathrm{~h})$ instead of for $2 \mathrm{~h}$. Fragments were separated on a CHEF-DRII (Bio-Rad Laboratories, Hercules, CA), using pulse times increasing from 2.16 to $54.17 \mathrm{~s}$ and a run time of $19 \mathrm{~h}$. The PFGE profiles were clustered with the BioNumerics version 5.10 software (Applied Maths, Sint-Martens-Latem, Belgium) using the Dice coefficient and the unweighted pair group method with arithmetic mean (UPGMA) clustering algorithm. Isolates with similarities of $95 \%$ or higher were assigned to the same pulsotype.

\section{Statistical Analyses}

Associations between the source of $K$. pneumoniae and the number of $K$. pneumoniae-positive samples were analyzed using Pearson $\chi^{2}$ test on contingency tables (SPSS version 17, 2010, SPSS Inc., Chicago, IL).

\section{RESULTS}

During the present study, 2,580 milk samples were collected from the cohort cows in lactation (monthly samples + clinical cases) and 64 extra samples of clinical mastitis cases were derived from the cows not belonging to the cohorts. The average IRCM (all cases) in the herds was 0.281 quarter cases per 365 cow-days at risk (ranging from 0.149 to 0.485 between herds). Fecal sampling of the cohort cows resulted in 728 samples in total. Because of the absence of bedding in 1 herd during the first 5 mo, 73 used and 73 unused bedding samples were collected. During the entire study, 3,518 samples were collected, from which $153(4.3 \%) \mathrm{K}$. pneumoniae isolates were recovered. In Table 1 , an overview is presented of the number of samples and the results of the bacteriological analysis and PFGE typing. In 1 of the 2,580 milk samples of the cohort cows, K. pneu- 
Table 1. Number of tested samples of milk, feces, used bedding, and unused bedding and overview of the results of the bacteriological analysis and pulsed field gel electrophoresis (PFGE) typing in 6 herds (A to F)

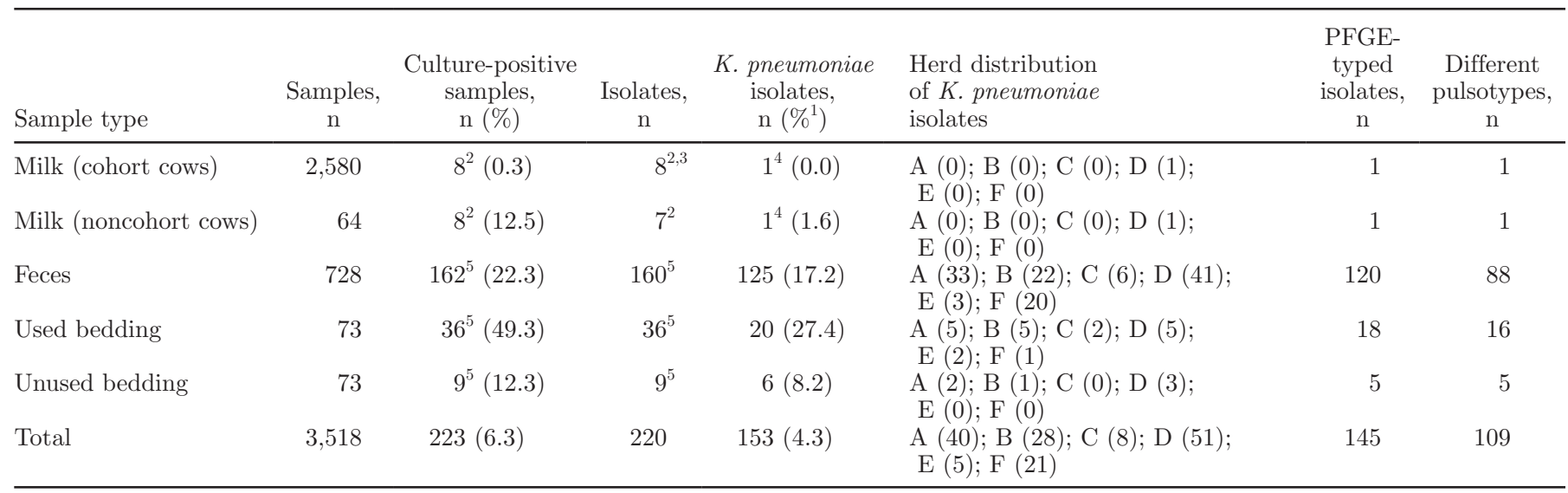

${ }^{1}$ Percentage of Klebsiella pneumoniae isolates out of the total number of samples.

${ }^{2}$ Lactose-fermenting, gram-negative bacteria.

${ }^{3}$ Three out of 8 isolates were derived from clinical samples.

${ }^{4}$ Derived from clinical sample.

${ }^{5}$ Klebsiella spp.

moniae was found (clinical case). From the samples of clinical cases derived from the cows not belonging to the cohorts, 1 more K. pneumoniae was isolated. Klebsiella pneumoniae was present in 17.2, 27.4, and $8.2 \%$ of the samples from feces, used bedding, and unused bedding, respectively. The number of $K$. pneumoniaepositive samples in unused bedding was significantly lower $(P<0.05)$ than that in used bedding and in both used bedding and feces combined. In the feces of 48 of the 74 cohort cows (65\%), K. pneumoniae was isolated at least once during the study.

In total, $153 \mathrm{~K}$. pneumoniae isolates were subjected to PFGE. Of these, 145 gave a PFGE pattern and were further analyzed (Table 1). Based on numerical analysis of the PFGE patterns, the 145 isolates were differentiated into 109 pulsotypes, 19 of which consisted of more than one isolate. Two pulsotypes contained isolates from different sources: pulsotype 10 was found in milk from a cohort cow (clinical mastitis case) and used bedding, and pulsotype 21 was found in both feces and used bedding (Figure 1). The $2 \mathrm{~K}$. pneumoniae isolates from milk originated from 2 cows in the same herd (herd D), but differed in PFGE pattern. In feces, 88 pulsotypes were detected ( 1 to 28 per herd), and in used bedding, 16 pulsotypes were found ( 1 to 4 per herd). The 5 isolates from unused bedding originated from 3 herds and all belonged to different pulsotypes. All isolates from the unused bedding belonged to pulsotypes other than those from other sources.

To illustrate relationships between isolates from different sources or samples of the same herd, the PFGE cluster of all isolates from herd D (from which the 2 milk isolates were obtained) is presented in Figure 1. In herd D, as well as in the other herds, isolates from feces with the same pulsotype were observed several times. Identical pulsotypes were often observed in feces of herdmates in the same month (shown in rectangles in Figure 1 for herd D), in feces of individual cows at different samplings [pulsotype 1 (cow 02) and pulsotype 4 (cow 08) for herd D (Figure 1)], and in feces of herdmates at different samplings. Most of the cows carried different $K$. pneumoniae pulsotypes in their feces during the study period. The number of cows shedding $K$. pneumoniae in feces differed substantially between herds (Table 1). In herd B and herd C, 2 isolates from used bedding displayed identical pulsotypes. In 4 cases, isolates originating from fecal samples from different herds showed an identical pulsotype as well.

\section{DISCUSSION}

A longitudinal study was conducted to sample quarters of several cows in 6 well-managed dairy farms to study the presence of IMI caused by K. pneumoniae and to identify potential $K$. pneumoniae sources. Lactosefermenting gram-negative bacteria were isolated from only 15 of 2,644 milk samples. Ten of these isolates were derived from clinical mastitis cases and 2 of these were shown to be $K$. pneumoniae. These $2 K$. pneumoniae isolates originated from 2 cows from the same herd with clinical mastitis signs and belonged to different pulsotypes. Concurrently, in feces, used bedding, and unused bedding, $151 \mathrm{~K}$. pneumoniae isolates were found. In spite of extensive sampling of the cohort cows 


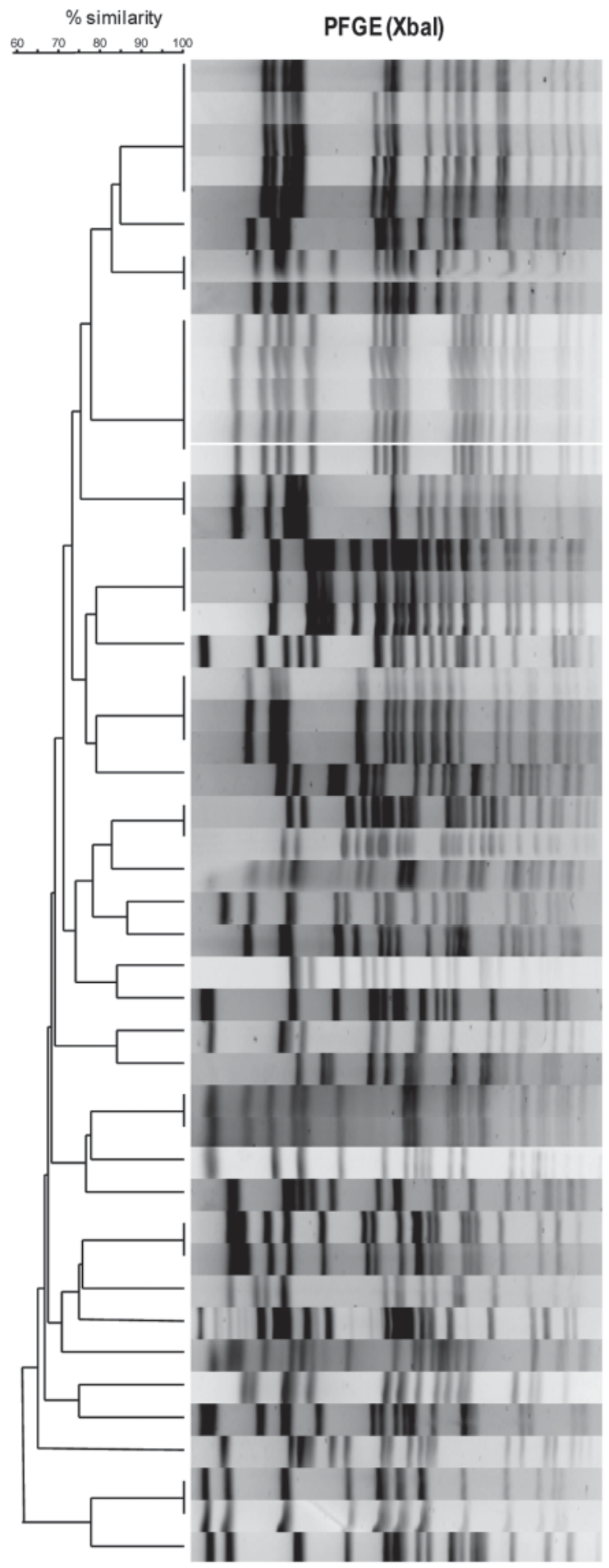

\section{Isolate Pulsotype Source Cow Sampling}

\begin{tabular}{|c|c|c|c|c|}
\hline COL 044 & 1 & feces & 04 & 3 \\
\hline COL 047 & 1 & feces & 07 & 3 \\
\hline COL 042 & 1 & feces & 02 & 3 \\
\hline COL 068 & 1 & feces & 02 & 4 \\
\hline COL 075 & 1 & feces & 10 & 4 \\
\hline COL 072 & 2 & feces & 06 & 4 \\
\hline COL 151 & 3 & feces & 04 & 7 \\
\hline COL 152 & 3 & feces & 05 & 7 \\
\hline COL 004 & 4 & feces & 04 & 1 \\
\hline COL 005 & 4 & feces & 07 & 1 \\
\hline COL 007 & 4 & feces & 10 & 1 \\
\hline COL 006 & 4 & feces & 08 & 1 \\
\hline COL 120 & 4 & feces & 08 & 5 \\
\hline COL 119 & 5 & feces & 05 & 5 \\
\hline COL 153 & 5 & feces & 06 & 7 \\
\hline COL 116 & 6 & feces & 01 & 5 \\
\hline COL 118 & 6 & feces & 04 & 5 \\
\hline COL 121 & 6 & feces & 10 & 5 \\
\hline COL 069 & 7 & feces & 03 & 4 \\
\hline COL 046 & 8 & feces & 06 & 3 \\
\hline COL 071 & 8 & feces & 05 & 4 \\
\hline COL 074 & 8 & feces & 08 & 4 \\
\hline COL 073 & 9 & feces & 07 & 4 \\
\hline COL 188 & 10 & used bedding & & 7 \\
\hline COL 213 & 10 & milk (cohort) & 22 & 12 \\
\hline COL 229 & 11 & feces & 22 & 13 \\
\hline COL 070 & 12 & feces & 04 & 4 \\
\hline COL 149 & 13 & used bedding & & 6 \\
\hline COL 174 & 14 & unused bedding & & 8 \\
\hline COL 194 & 15 & feces & 13 & 10 \\
\hline COL 026 & 16 & feces & 08 & 2 \\
\hline COL 077 & 17 & milk (non-cohort) & 16 & 4 \\
\hline COL 226 & 18 & feces & 22 & 12 \\
\hline COL 227 & 18 & feces & 05 & 13 \\
\hline COL 038 & 19 & used bedding & & 2 \\
\hline COL 154 & 20 & feces & 07 & 7 \\
\hline COL 066 & 21 & used bedding & & 3 \\
\hline COL 117 & 21 & feces & 03 & 5 \\
\hline COL 045 & 22 & feces & 05 & 3 \\
\hline COL 122 & 23 & feces & 13 & 5 \\
\hline COL 228 & 24 & feces & 10 & 13 \\
\hline COL 008 & 25 & unused bedding & & 1 \\
\hline COL 155 & 26 & feces & 08 & 7 \\
\hline COL 027 & 27 & feces & 09 & 2 \\
\hline COL 043 & 28 & feces & 03 & 3 \\
\hline COL 049 & 28 & feces & 13 & 3 \\
\hline COL 130 & 29 & unused bedding & & 5 \\
\hline
\end{tabular}

Figure 1. Pulsed field gel electrophoresis (with digestion using XbaI) clustering of Klebsiella pneumoniae isolates from milk (both clinical samples), feces, used bedding, and unused bedding, all originating from herd D. Percentage of genetic similarity, which was calculated using the Dice coefficient, is shown (scale in the upper left corner). Isolates with similarities of $95 \%$ or higher were assigned to the same pulsotype. Isolates with the same pulsotype are linked with a vertical line. Isolates with the same pulsotype originating from samples of the same month are indicated in rectangles. 
and of all clinical cases in the herds (originating from both cohort and noncohort cows), no IMI caused by $K$. pneumoniae were found in 5 of the 6 herds, although $K$. pneumoniae was abundantly present in the environment. The incidence rates of clinical mastitis on the 6 herds were comparable with other reports (Barkema et al., 1998), suggesting that IMI-causing $K$. pneumoniae was not underestimated. It appears that $K$. pneumoniae can be prevalent in the environment of the cows without causing significant mastitis problems.

Clearly, K. pneumoniae found in the environment were not very likely to cause IMI. However, the pulsotype of one of the milk isolates of herd D was identical to that of a used bedding isolate found 5 mo earlier within that herd. This indicates that with extended environmental sampling, it is possible to trace IMIcausing $K$. pneumoniae strains in the environment. This may also illustrate that the strains of IMI-causing $K$. pneumoniae were not necessarily other strains than the environmental strains, as previously observed by Munoz et al. (2007) and Paulin-Curlee et al. (2008).

In our study, only the presence of $K$. pneumoniae was investigated. Consequently, the exact level of bacteria in the different sources (cfu/unit of measure) and the level of exposure of the teats to $K$. pneumoniae remain unknown. The role of the farm managers in reducing exposure of the teats to K. pneumoniae (and mastitiscausing pathogens in general) via management (e.g., housing, milking, hygiene) was not evaluated in depth, although we know this is important in prevention of IMI. The herds in this study were well managed. We believe the efforts of the farmers in keeping the cubicles and alleys clean substantially reduced the likelihood of IMI in our study. Many other factors related to the host (e.g., immunity, energy balance, genetic background) and the pathogen (e.g., virulence, virulence expression) influence the risk of IMI. Therefore, in this study, we can draw no definite conclusions regarding the relevance of $K$. pneumoniae and the risk of infection. Still, our qualitative approach illustrates the genetic diversity in $K$. pneumoniae and the potential links between different sources.

The present study is the first to show that most cows $(65 \%)$ in European herds harbor K. pneumoniae in the intestine, which is not in line with a recent Swedish report that few cows shed $K$. pneumoniae in feces (Lektonius et al., 2010). Although herd size, average BMSCC levels, feeding strategies, and so on differ considerably between European and American herds, our findings agree with those of Munoz and Zadoks (2007). The overall proportion of $K$. pneumoniae-positive feces samples $(22.3 \%)$ in our study is relatively low compared with the results of Munoz et al. (2006; 84\%) and Munoz and Zadoks $(2007 ; 81 \%)$. This could be explained by the variation in fecal $K$. pneumoniae shedding at the herd and cow levels (Munoz et al., 2006, 2007; Munoz and Zadoks, 2007). In addition, the between-herd differences will be related to intrinsic herd factors such as feeding (e.g., starch content), housing, or cleaning strategies.

The strain diversity of $K$. pneumoniae in dairy farms is best illustrated by the fecal $K$. pneumoniae isolates. Still, the $K$. pneumoniae heterogeneity is most probably underestimated because only one isolate per sample was strain-typed in our study. Although one K. pneumoniae pulsotype was found in fecal samples of 1 cow in 2 consecutive months, most of the cows carried different $K$. pneumoniae pulsotypes at different samplings. These results are in concordance with the observation of Munoz and Zadoks (2007) that the excretion of $K$. pneumoniae is a transient rather than a persistent process.

Despite the high discriminatory power of the PFGE typing technique, isolates of the same pulsotype were often found in feces of herdmates at the same sampling. According to the theory of an orofecal passage (Munoz and Zadoks, 2007), this is most likely due to herdmates orally picking up the same $K$. pneumoniae pulsotype from the environment and excreting it simultaneously. The synchronism of the excretion generates the hypothesis of the entrance of $K$. pneumoniae strains in the digestion tract from a common yet unknown source. As K. pneumoniae has previously been isolated from feed (Zadoks et al., 2011) and drinking water (Nonnecke and Newbould, 1984; Munoz et al., 2007; Zadoks et al., 2011), these could be possible sources.

Strain similarity in feces and used bedding was affirmed with the PFGE technique. Notwithstanding the systematic sampling and the plethora of K. pneumoniaepositive samples, isolates from the same pulsotype from feces and used bedding were found only once. This is likely due to the underestimation of strain diversity within a sample, but it is also at least partly due to the fact that in this experimental set-up, feces were sampled from $\leq 20 \%$ of the cows in each herd, whereas bedding was sampled from locations accessible to all cows of the herd. Moreover, fecal sampling and bedding sampling were executed on 2 different sampling days. Combined with the removal of used bedding at least twice a day and the fact that a cow can randomly excrete different $K$. pneumoniae strains over time (Munoz and Zadoks, 2007), the chance of finding an isolate of the same pulsotype in a fecal sample and in a used bedding sample is probably severely diminished. However, the above-mentioned strain similarity, the significant difference in the presence of $K$. pneumoniae between unused bedding and used bedding, and the fact that most of the cohort cows excreted $K$. pneumoniae in 
feces confirm that used bedding might be considered a fecally contaminated part of the environment, in agreement with the observations of Munoz et al. (2006).

Until recently, wood-based bedding materials were considered the most important way of entrance for Klebsiella in dairy herds (Vecht et al., 1987; National Mastitis Council, 1999; Sampimon et al., 2006). Our study confirms that $K$. pneumoniae can be present in unused sawdust bedding. However, the number of $K$. pneumoniae isolates found was significantly lower in the unused bedding than in the other sources. Moreover, it is intriguing that isolates from unused bedding in the current study belonged to pulsotypes other than those of the many isolates from milk, feces, or used bedding of the corresponding herds. These findings challenge our previous beliefs that unused bedding acts as an important source of $K$. pneumoniae in the herd.

Not one specific source of $K$. pneumoniae has been identified until now. As feces contaminate the environment, further research on the oral uptake and the orofecal transit of $K$. pneumoniae in cows is recommended. Second, we recommend the investigation of herd- and cow-level risk factors that could explain variation in fecal $K$. pneumoniae shedding and in presence of $K$. pneumoniae IMI. Third, differences in virulence mechanisms and tools for host immunity evasion between host-adapted (IMI causing) and environmental $K$. pneumoniae strains should be investigated, as this could lead to adjusted prevention strategies, successful treatment, and development of vaccines.

\section{CONCLUSIONS}

Monthly sampling and strain typing of $K$. pneumoniae with PFGE, a highly discriminating genotyping method, at the cow and environmental level in 6 well-managed dairy farms resulted in the detection of many different $K$. pneumoniae pulsotypes in the environment, whereas only 2 IMI-causing $K$. pneumoniae strains were detected. A high proportion of cows shed K. pneumoniae in feces as has been shown before under US farming conditions, which differ considerably from European farming conditions. Fecal contamination of bedding with $K$. pneumoniae was confirmed, whereas unused sawdust was not a source of $K$. pneumoniae for the environment of the cow.

\section{ACKNOWLEDGMENTS}

This research was funded by the Institute for the Promotion of Innovation through Science and Technology in Flanders (IWT-Vlaanderen, grant no. 60714). The authors thank Ann Vanhee and Nathan Van der Eecken [Institute for Agricultural and Fisheries Re- search (ILVO), Melle, Belgium] for the excellent laboratory support and Jeroen Debruyne and the technical staff of ILVO (Merelbeke, Belgium) for the field work support.

\section{REFERENCES}

Barkema, H. W., Y. H. Schukken, T. J. Lam, M. L. Beiboer, H. Wilmink, G. Benedictus, and A. Brand. 1998. Incidence of clinical mastitis in dairy herds grouped in three categories by bulk milk somatic cell counts. J. Dairy Sci. 81:411-419.

Erskine, R. J., P. C. Bartlett, J. L. VanLente, and C. R. Phipps. 2002a. Efficacy of systemic ceftiofur as a therapy for severe clinical mastitis in dairy cattle. J. Dairy Sci. 85:2571-2575.

Erskine, R. J. J. W. Tyler, M. G. Riddell Jr., and R. C. Wilson. 1991. Theory, use, and realities of efficacy and food safety of antimicrobial treatment of acute coliform mastitis. J. Am. Vet. Med. Assoc. 198:980-984.

Erskine, R. J., R. D. Walker, C. A. Bolin, P. C. Bartlett, and D. G. White. 2002b. Trends in antibacterial susceptibility of mastitis pathogens during a seven-year period. J. Dairy Sci. 85:1111-1118.

Gröhn, Y. T., D. J. Wilson, R. N. Gonzalez, J. A. Hertl, H. Schulte, G. Bennett, and Y. H. Schukken. 2004. Effect of pathogen-specific clinical mastitis on milk yield in dairy cows. J. Dairy Sci. 87:3358-3374.

Hogan, J. S., K. L. Smith, K. H. Hoblet, D. A. Todhunter, P. S. Schoenberger, W. D. Hueston, D. E. Pritchard, G. L. Bowman, L. E. Heider, B. L. Brockett, and H. R. Conrad. 1989. Bacterial counts in bedding materials used on nine commercial dairies. J. Dairy Sci. 72:250-258.

Kikuchi, N., C. Kagota, T. Nomura, T. Hiramune, T. Takahashi, and R. Yanagawa. 1995. Plasmid profiles of Klebsiella pneumoniae isolated from bovine mastitis. Vet. Microbiol. 47:9-15.

Lektonius, M., H. Ericsson Unnerstad, A. Aspán, and K. Persson Waller. 2010. Klebsiella pneumoniae in feces: A risk factor for mastitis in Swedish dairy cows? Pages 674-675 in Mastitis Research into Practice: Proc. 5th IDF Mastitis Conf., Christchurch, New Zealand. International Dairy Federation, Brussels, Belgium.

Liu, Y., C. Liu, W. J. Zheng, X. Zhang, J. Yu, Q. L. Gao, Y. M. Hou, and X. T. Huang. 2008. PCR detection of Klebsiella pneumoniae in infant formula based on 16S-23S internal transcribed spacer. Int. J. Food Microbiol. 125:230-235.

Munoz, M. A., C. Ahlstrom, B. J. Rauch, and R. N. Zadoks. 2006. Fecal shedding of Klebsiella pneumoniae by dairy cows. J. Dairy Sci. 89:3425-3430

Munoz, M. A., F. L. Welcome, Y. H. Schukken, and R. N. Zadoks. 2007. Molecular epidemiology of two Klebsiella pneumoniae mastitis outbreaks on a dairy farm in New York State. J. Clin. Microbiol. 45:3964-3971.

Munoz, M. A., and R. N. Zadoks. 2007. Short communication: Patterns of fecal shedding of Klebsiella by dairy cows. J. Dairy Sci. 90:1220-1224.

National Mastitis Council. 1999. Laboratory Handbook on Bovine Mastitis. National Mastitis Council, Madison, WI.

National Mastitis Council. 2008. Recommended Mastitis Control Program. Accessed Aug. 1, 2010. http://www.nmconline.org/docs/ NMCchecklistInt.pdf.

Nomura, T., H. Moriya, N. Kikuchi, and T. Hiramune. 1989a. Capsular types of Klebsiella associated with bovine mastitis in Japan. Nippon Juigaku Zasshi 51:1287-1289.

Nomura, T., H. Sugiura, H. Moriya, N. Kikuchi, T. Hiramune, and R. Yanagawa. 1989b. Species and capsular types of Klebsiella isolated from cows and their environment. J. Rakuno Gakuen Univ. 14:57-61.

Nonnecke, B. J., and F. H. S. Newbould. 1984. Biochemical and serologic characterization of Klebsiella strains from bovine mastitis and the environment of the dairy cow. Am. J. Vet. Res. 45:2451-2454.

Paulin-Curlee, G. G., R. S. Singer, S. Sreevatsan, R. Isaacson, J. Reneau, D. Foster, and R. Bey. 2007. Genetic diversity of mastitis-associated Klebsiella pneumoniae in dairy cows. J. Dairy Sci. 90:3681-3689 
Paulin-Curlee, G. G., S. Sreevatsan, R. S. Singer, R. Isaacson, J. Reneau, R. Bey, and D. Foster. 2008. Molecular subtyping of mastitisassociated Klebsiella pneumoniae isolates shows high levels of diversity within and between dairy herds. J. Dairy Sci. 91:554-563.

Piepers, S., L. De Meulemeester, A. de Kruif, G. Opsomer, H. W. Barkema, and S. De Vliegher. 2007. Prevalence and distribution of mastitis pathogens in subclinically infected dairy cows in Flanders, Belgium. J. Dairy Res. 74:478-483.

Ribeiro, M. G., R. G. Motta, A. C. Paes, S. D. Allendorf, T. Salerno, A. K. Siqueira, M. C. Fernandes, and G. H. B. Lara. 2008. Peracute bovine mastitis caused by Klebsiella pneumoniae. Arq. Bras. Med. Vet. Zootec. 60:485-488.

Ribot, E. M., M. A. Fair, R. Gautom, D. N. Cameron, S. B. Hunter, B Swaminathan, and T. J. Barrett. 2006. Standardization of pulsedfield gel electrophoresis protocols for the subtyping of Escherichia coli O157:H7, Salmonella, and Shigella for PulseNet. Foodborne Pathog. Dis. 3:59-67.

Roberson, J. R., L. D. Warnick, and G. Moore. 2004. Mild to moderate clinical mastitis: Efficacy of intramammary amoxicillin, frequent milk-out, a combined intramammary amoxicillin, and frequent milk-out treatment versus no treatment. J. Dairy Sci. 87:583-592.

Sampimon, O. C., J. Sol, and P. A. Kock. 2006. An outbreak of Klebsiella pneumoniae mastitis. Tijdschr. Diergeneeskd. 131:2-4.
Silva, N., and G. M. Costa. 2001. An outbreak of acute bovine mastitis caused by Klebsiella pneumoniae in a dairy herd. Arq. Bras. Med. Vet. Zootec. 53:1-5.

Todhunter, D. A., K. L. Smith, J. S. Hogan, and P. S. Schoenberger. 1991. Gram-negative bacterial infections of the mammary gland in cows. Am. J. Vet. Res. 52:184-188.

Vecht, U., K. C. H. M. Meijers, and H. J. Wisselink. 1987. Klebsiella pneumoniae mastitis in a dairy herd. Tijdschr. Diergeneeskd. 112:653-659

Zadoks, R. N., H. M. Griffiths, M. A. Munoz, C. Ahlstrom, G. J. Bennett, E. Thomas, and Y. H. Schukken. 2011. Sources of Klebsiella and Raoultella species on dairy farms: Be careful where you walk. J. Dairy Sci. 94:1045-1051.

Zadoks, R. N., M. A. Munoz, H. Griffiths, G. Bennett, and Y. H. Schukken. 2008. Klebsiella - Not by bedding alone. Pages 240-241 in Proc. NMC 47th Annual Meeting. New Orleans, Louisiana.

Zdanowicz, M., J. A. Shelford, C. B. Tucker, D. M. Weary, and M. A. G. von Keyserlingk. 2004. Bacterial populations on teat ends of dairy cows housed in free stalls and bedded with either sand or sawdust. J. Dairy Sci. 87:1694-1701. 